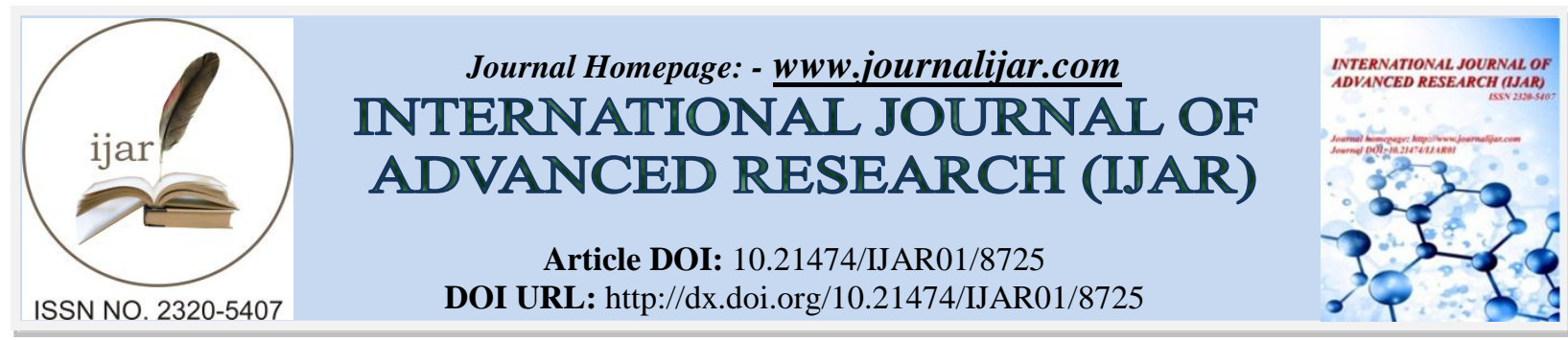

RESEARCH ARTICLE

\title{
PSEUDOCYST OF PINNA: EFFICACY OF CARTILAGE WINDOW WITH BUTTON TECHNIQUE - TERTIARY CARE EXPERIENCE.
}

\author{
Dr. Asif Mahajan ${ }^{1}$, Dr. Shahnaz Sheikh ${ }^{2}$ and Dr. Omar Ashraf Beigh ${ }^{3}$. \\ 1 Senior Resident, Department of ENT, H\&NS, SKIMS-MC, Srinagar (J\&K) India. \\ 2 Senior Resident, Department of ENT, H \& NS, Dr. Ulhas Patil Medical College, Jalgaon, Maharashtra, India. \\ 3 Senior Resident, Department of ENT, H\&NS, SKIMS-MC, Srinagar (J\&K) India.
}

\section{Manuscript Info}

\section{Manuscript History}

Received: 17 January 2019

Final Accepted: 19 February 2019

Published: March 2019

Key words:-

Pseudocyst, pinna, perchondritis.

\begin{abstract}
Background: Pseudocyst of the pinna is a benign, idiopathic, painless, spontaneous dome shaped cystic swelling on the anterior surface of the auricle. It is a difficult condition to treat medically or surgically and a large number of treatment modalities have been described in the literature. Definitive treatment still remains controversial.

Aim: To study the effectiveness of cartilage window with buttoning technique in the treatment of pseudocyst of the pinna.

Methods: A prospective study at a tertiary care centre for a period of one year, which included 26 patients with diagnosis of pseudocyst pinna. All the patients were treated by excising the small cartilage window and using the buttoning technique for compression and were followed up after one week and one month of surgery.

Results: All the 26 cases were completely relieved off the disease at the end of one month and none showed any recurrence. None of our patients had any postoperative complications like perichondritis of pinna or any structural deformities.

Conclusion: The surgical treatment of pseudocyst pinna by making a cartilage window with buttoning technique is an excellent for treatment of pseudocyst pinna.
\end{abstract}

Copy Right, IJAR, 2019,. All rights reserved.

\section{Introduction:-}

Pseudocyst of the pinna is a benign, idiopathic, painless, spontaneous dome shaped cystic swelling on the anterior surface of the auricle ${ }^{1,2,3}$.

Histologically, it is an intracartilaginous cyst devoid of an epithelial lining (hence named pseudocyst). It contains straw or yellow coloured, viscous, albumin containing fluid with osmolarity, glucose and protein concentration similar to that of plasma ${ }^{4}$.

It is a difficult condition to treat medically or surgically and a large number of treatment modalities have been described in the literature. Definitive treatment still remains controversial. Goal of the treatment should be to preserve or restore the normal architecture of the auricle with no recurrence ${ }^{4}$. We present our experience of 26 patients of pseudocyst of pinna in which we aimed to evaluate the effectiveness of combining the cartilage window and button technique in treatment of pseudocyst pinna. 
Aim Of The Study:-

To study the effectiveness of cartilage window with buttoning technique in the treatment of pseudocyst of the pinna.

\section{Materials And Methods:-}

The present prospective study was conducted in the Department of ENT, H\&NS, SKIMS Medical College and Hospital, Bemina Srinagar. Twenty-six patients with pseudocysts of the pinna were enrolled in the study for a period of one year from March 2016 to March 2017 after they understood and accepted the procedure. Pseudocysts were diagnosed on the basis of clinical presentation, characteristics of the aspirated fluids, no evidence of infection, and absent signs of inflammation. The patients in the study group were treated surgically by the cartilage window and buttoning method under local anaesthesia. They were followed up for a period of one month to look for any recurrence.

The cartilage is exposed and a small incision of about $0.5 \mathrm{~cm}$ is made on the cartilage which would immediately drain the fluid collection in the pseudocyst. Once the fluid is drained out completely, a cartilage piece of size $0.5 \times 0.5$ $\mathrm{cm}$ is cut off taking care not to injure the opposite perichondrium, thus creating a cartilage window. The skin incision was sutured with 3-0 black silk. Next, two sterilized small shirt buttons are placed on either side of the pinna corresponding to the site of the pseudocyst and sutured through and through using 2-0 black silk. Care is taken that the buttons are just tight enough to compress the two skin surface and to avoid too much pressure. No mastoid bandage dressing is given. The patient is prescribed antibiotics and local antiseptics for one week.

The sutures and the buttons are removed after one week, and recurrence if any, were noted. The patients are then followed-up after one month to look for any recurrence. The findings were noted and the results analysed.

\section{Results:-}

A total of 26 cases attended our outpatient department during the study period with a diagnosis of pseudocyst pinna. The age group of the patients ranged from 21 to 50 ears. There were 24 males and 2 females in our study strengthening the fact that this condition affects mostly males. Maximum numbers (i.e. 11) of patients were in the age group of 31-40 comprising about $42 \%$ of study population [Table 1]. Maximum number of patients i.e. 10 had swelling involving predominantly triangular, scaphoid fossa. The scaphoid fossa was involved in 4 cases (15.3\%) and the triangular fossa was involved in 5 cases (19.2\%). Involvement of both right and left ears was seen, but left ear was involved more than right with 16 and 10 cases respectively. None of the cases had bilateral pseudocyst. The fluid aspirated was straw colored in majority of patients i.e. 15 while 2 patients had serosanguinous fluid. The volume of the fluid ranged from $1-5 \mathrm{ml}$. The size of the swelling ranged from 1.5 to $5 \mathrm{~cm}$ in largest diameter (Table 4).

\begin{tabular}{|l|l|l|l|}
\hline \multicolumn{4}{|l|}{ Table 1: Age and sex distribution of patients } \\
\hline Age group in years & Male & Female & Total \\
\hline$<10$ & 0 & 0 & 0 \\
\hline $11-20$ & 2 & 0 & 2 \\
\hline $21-30$ & 4 & 1 & 5 \\
\hline $31-40$ & 10 & 1 & 11 \\
\hline $41-50$ & 6 & 0 & 6 \\
\hline $51-60$ & 2 & 0 & 2 \\
\hline
\end{tabular}

\begin{tabular}{|l|l|l|}
\hline Table 2: Sites of involvement & Percentage \\
\hline Sites & Number of cases & 38.5 \\
\hline Triangular fossa and scaphoid fossa & 10 & 19.2 \\
\hline Triangular fossa & 5 & 15.4 \\
\hline Scaphoid fossa & 4 & 15.4 \\
\hline Diff use swelling & 4 & 11.5 \\
\hline Concha & 3 & 100.00 \\
\hline Total number of patients & 26 & \\
\hline
\end{tabular}

All the patients were treated by the cartilage window and buttoning technique as described above and were followed-up after one week and one month of surgery. None of our cases had a reaccumulation of fluid at the time of suture removal after one week. All the 26 cases were completely relieved of the disease at the end of one month and none showed a recurrence. None of our patients had any postoperative complications like perichondritis of pinna 
or any structural deformities. Thus the surgical treatment of pseudocyst pinna by the cartilage window with buttoning technique gave a reliable result in all cases.

\begin{tabular}{|l|l|l|}
\hline Table 3: No. of patients with recurrence of disease \\
\hline Procedure & $\begin{array}{l}\text { Number of cases primarily } \\
\text { done }\end{array}$ & $\begin{array}{l}\text { Number of recurrent/ } \\
\text { persistent cases }\end{array}$ \\
\hline Cartilage window with buttoning & 26 & 0 \\
\hline
\end{tabular}

\begin{tabular}{|c|c|c|}
\hline \multicolumn{2}{|c|}{ Characteristics } & Number of cases \\
\hline \multirow[t]{3}{*}{ Color of fluid } & Serasanguinous & 2 \\
\hline & Straw serum & 15 \\
\hline & Yellow & 9 \\
\hline \multicolumn{2}{|c|}{ Size of swelling $(\mathrm{cm})$} & $1.5-5$ \\
\hline \multicolumn{2}{|c|}{ Volume of fluid (ml) } & $1-5$ \\
\hline \multirow{4}{*}{ Laterality } & Right & 10 \\
\hline & Left & 16 \\
\hline & Unilateral & 26 \\
\hline & Bilateral & 0 \\
\hline
\end{tabular}

\section{Discussion:-}

Pseudocyst of the pinna has also been referred to as an intracartilaginous cyst, an endochondral pseudocyst, and cystic chondromalacia of the auricle ${ }^{5}$. In this condition there is a spontaneous accumulation of sterile fluid in the intercartilaginous plane, presenting as a painless cystic swelling on the upper portion of the pinna, with normal overlying $\operatorname{skin}^{6}$.

Histologically, pseudocyst is characterized by an intracartilaginous cavity lacking in epithelial lining (hence named pseudocyst), ${ }^{7}$ and contain thinned cartilage and hyalinising degeneration along the internal border of the cystic space and granulation tissue. ${ }^{8}$

Even though the exact etiology of pseudocyst of the auricle is unknown, two main theories have been proposed. The first theory suggests that the pseudocyst is often the result of repeated minor low grade trauma, such as rubbing, pulling the ear, sleeping on hard pillows ${ }^{9}$ or wearing a motorcycle helmet or headphones ${ }^{10}$. It was suggested that chronic trauma would induce cartilage degeneration resulting in progressive dilatation and formation of a cystic space within the auricular cartilage ${ }^{11}$. The second theory attributed a congenital embryologic defect of the auricular cartilage in the development of the pseudocyst. The congenital maldevelopment of first and second branchial arch may result in residual tissue planes within the cartilage which may later reopen, giving rise to a pseudocyst ${ }^{12}$. Another proposed etiological factor is the ${ }^{13}$ accumulation of reactive exudates due to immunoreactions of autologous antibody and auricular tissue. Young children are rarely affected as seen in our study and in other studies. $^{14}$

Different forms of treatment have been described in several case reports and small series to overcome the recurrence. Surgical deroofing by excision of the anterior wall of the cyst, as a treatment of pseudocyst was first described by Choi ${ }^{15}$, who got very good results in $90 \%$ of his 31 patients using contour dressings for compression. $\mathrm{Lim}^{16}$ modified this technique by using buttoning as a compression method in his group of 41 patients and reported no recurrence with good cosmetic outcome in all the patients. The use of buttoning by Lim gave the advantage of providing a constant compression as compared to contour dressings, leading to a better result. Similarly Nazir A Khan et $a l^{17}$, showed $96 \%$ efficacy of deroofing procedure in their study. Satheesh Bhandary et al ${ }^{18}$, treated 30 pseudocyst cases with different modalities like wide bore needle aspiration, intracavitary steroid injection and window de-roofing procedure. Among them, the window de-roofing procedure was found to be successful in $100 \%$ of the cases with a minimum of sequelae.

In a study by Vinay $\mathrm{S}$ et $\mathrm{al}^{19}, 30$ patients underwent surgical deroofing of the pseudocyst along with compression buttoning. All 29 patients $(96.7 \%)$ had no recurrence and the failure in one case was attributed to the use of improper buttons for compression. 
Ayaz Rehman et $a l^{20}$ divided 41 patients of pseudocyst with recurrence after needle aspiration and intralesional steroid injection into two groups. Group I comprising of 26 patients, underwent incision and drainage with curettage followed by buttoning and group II comprising of 15 patients, underwent surgical deroofing of the cyst along with buttoning. 7 of the 26 patients showed recurrence after incision and drainage with buttoning whereas the 15 patients who underwent surgical deroofing with buttoning showed no recurrence.

In our study we have combined the technique of creating a cartilage window in the pinna followed by the buttoning technique for providing the constant compression. In all our 26 patients there were no recurrences, no infection or perichondritis of the pinna or any structural deformities. Thus combining the two reliable methods in the treatment of this condition would ensure a $100 \%$ success. The use of buttoning for compression ensured that a constant pressure is maintained during the first week after surgery, thus preventing any reaccumulation of fluid. Moreover, the use of dark coloured buttons would camouflage its presence and would be cosmetically more acceptable for the patient. So the buttoning technique avoids the use of postoperative drains or mastoid bandage for the patient.

One of the main disadvantages of the surgical deroofing surgery is the chance of developing a perichondritis, as a part of the anterior skin is removed, and the second one being an ugly scar. Even in the other techniques described by some authors, the scar in the anterior part of the pinna was an evident cosmetic problem. Our technique of using the posterior incision would be cosmetically accepted better by the patient. Since we just excise a very small part of the cartilage for creating the window, the chance of developing any structural deformity is also minimised.

\section{Conclusion:-}

The surgical treatment of making a cartilage window along with buttoning technique is an excellent method for the treatment of pseudocyst pinna. This method is reliable and safe ensuring a successful treatment with minimum chance of recurrence. It is relatively free of any complications. Moreover our method of using a posterior incision provides a good cosmetic result.

\section{References:-}

1. Beck K. Uber Zystenbildung am Nasenfl"ugel. European Archives of Oto-Rhino-Laryngology. 1911; 85(4): 304-07.

2. Engel D. Pseudocysts of the auricle in Chinese. Archives of Otolaryngology. 1966; 83(3): 197-202.

3. Chen Q, Zhao T, Yang X. The immunological cause of auricular pseudocyst. Zhonghua er bi yan hou ke za zhi. 1999; 34(4): 236-37.

4. Schulte KW, Neumann NJ, Ruzicka T. Surgical pearl: the close-fitting ear cover cast-a noninvasive treatment for pseudocyst of the ear. J Am Acad Dermatol. 2001; 44(2): 285-86.

5. Cohen PR, Grossman ME. Pseudocyst of the auricle. Case report and world literature review. Arch Otolaryngol Head Neck Surg 1990; 116: 1202-4.

6. Koirala K, Rai S et al. Comparision between posterior cartilage window and aspiration and quilting technique in treatment of pseudocyst of pinna. Nepalese Journal of ENT Head and Neck Surgery. 2; 2(2):10-12.

7. Choi S, Lam K, Chan KW, Cohadially FN, Anthony SM. Endochondral pseudocyst of the auricle in Chinese. Arch Otolaryngol 1984; 110:792-6.

8. Ramadass T, Ayyaswamy G. Pseudocyst of auricle etiopathogenesis, treatment update and literature review. Indian J Otolaryngol Head Neck Surg 2006; 58: 156-9.

9. Engel D. Pseudocyst of the auricle in Chinese. Arch otolaryngol 1966; 83:197-202.

10. Glamb R, Kim R. Pseudocyst of the auricle. J Am Acad Dermatol 1984; 11: 58-63.

11. Choi S, Lam KH, Chan KW et al. Endochondral pseudocyst of the auricle in Chinese. ArchOtolaryngol 1984; 110:792-96.

12. Lee JA, Panarese A. Endochondral pseudocyst of the auricle. J Clin Pathol 1994; 47:961-3.

13. Chen Q, Zhao T, Yang X. Immunological cause of auricular pseudocyst. Zhanghua Er Bi Yan Hou Ke Za Zhi 1999; 34:236-7.

14. Supiyaphun P, Decha W. Auricular pseudocysts: A treatment with the Chulalongkorn University vacuum device. Otolaryngol Head Neck Surg 2001; 124: 213-6.

15. Hansen JE. Pseudocyst of the auricle in Caucasians. Arch Otolaryngol 1967; 85: 1-13.

16. Devlin J, Harrison CJ, Whitby DJ. Cartilaginous pseudocyst of the external auricle in children with atopic eczema. Br J Dermatol 1990; 112: 699-704. 
17. Karabulut H, Acar B, Selcuk K. Treatment of the nontraumatic auricular pseudocyst with aspiration and intralesional steroid injection. New J Med 2009; 26: 117-9.

18. Kanotra SP, Lateef M. Pseudocyst of pinna: A recurrence ree approach. Am J Otolaryngol 2009; 30: 73-9.

19. Vinay S, Shilpa, Nitha et al. Auricular Pseudocyst: Our Experience with Deroofing and Compression Procedure. Journal of Clinical and Diagnostic Research. 2014; 8(10): KC05-KC07.

20. Ayaz Rehman, Mushtaq A Sangoo et al. Recurrent Pseudocyst Pinna: A Rational Approach to Treatment International Journal of Scientific and Research Publications, 2013; 3(7): 5-7. 